\title{
Marketing responsible tourism
}

\section{Clare Weeden}

\section{Introduction}

This chapter provides an overview of some of the key challenges that face those tasked with marketing responsible tourism. It begins with a brief review of the ethical issues that dominate discussion of tourism's impact, and an articulation of the main drivers for responsible tourism. The chapter defines responsible tourism, discusses some of the major barriers to increasing demand for responsible holidays, and reflects on the various marketing methods adopted by tour operators in this industry. The chapter concludes with recommendations for future consideration.

\section{The success of mass tourism}

Each year millions of people travel, take holidays and pursue leisure experiences in pursuit of self-discovery, relaxation and pleasure (Weeden 2013). Because such aspirations are often considered essential to life in post-industrial society, demand for travel has grown exponentially during the past 60 years. As a consequence, 4.8 billion international and domestic trips were taken in 2011 (UNWTO 2012a), while the forecasted increase in demand from the BRIC countries of Brazil, Russia, India and China means 1.8 billion international and 7 billion domestic trips will be taken by 2030 (UNWTO 2011; UNWTO 2012b). Although tour operators may be delighted with such success and happy to meet the commercial opportunities presented by these forecasts, not everyone is pleased with the style of tourism's development, and not all stakeholders believe they benefit equally from tourist expenditure. For instance, while tourism undoubtedly brings economic benefit, some question whether an industry renowned for its propensity to offer high volume, low price tourism to the mass market can ever be truly sustainable and conform to socially just and equitable principles (Cleverdon and Kalisch 2000; Wearing 2002; Higgins-Desbiolles 2008). 
In response to such criticism, commentators have spent decades debating various types of 'alternative tourism', discussing what these approaches might look like, and trying to establish how they could be sold successfully to the market place (see for example Eagles et al. 2002; Kalisch 2001; Scheyvens 2002). The most well established of these proposed alternatives are ecotourism, community-based tourism, Pro-poor tourism, Fair Trade tourism, ethical tourism and responsible tourism. While debate continues as to the individual merits of these related concepts, tensions over terminology have detracted from the message that consumers and industry must move together towards the goal of taking responsibility in tourism (Cooper and Ozdil 1992). Whilst clearly prioritising different aspects of tourism and travel, individually and collectively the aim of these alternatives are to foster a just and equitable approach to the development, operation and management of tourism. Such aspirations are critical to the future success of the industry, which is coming under 'increasing international pressure [...] to address issues of global warming, social inequality and diminishing natural resources’ (Frey and George 2008:107). Indeed, calls have long been made for the tourism and travel industry to refocus attention on sustaining fair and cooperative relationships rather than relying on unjust appropriation of human and non-human capital (see for example Font and Ahjem 1998; Forsyth 1997; Hultsman 1995; Payne and Dimanche 1996). Responsibility in tourism and responsible forms of tourism are increasingly considered fundamental to the industry's future success (see Leslie 2012).

\section{Defining responsible tourism}

With its roots in the concept of sustainable tourism, responsible tourism has developed from the understanding that 'tourism-related actors can develop a sense of ethical and moral responsibility that has resonance beyond self-interest' (Bramwell et al. 2008:253). This idea that tourism should deliver benefits to a range of stakeholders, and not just operate for the pleasure of the tourist, is inherent in the following definition,

Responsible tourism minimises negative economic, environmental, and social 
impacts, generates greater economic benefits for local people and enhances the well-being of host communities. It aims to improve working conditions and access to the industry, involve local people in decisions that affect their lives and life chances, and make positive contributions to the conservation of natural and cultural heritage and to the maintenance of the world's diversity. Responsible tourism also strives to provide more enjoyable experiences for tourists through more meaningful connections with local people, and a greater understanding of local cultural, social and environmental issues. It provides access for physically challenged people, is culturally sensitive, and engenders respect between tourists and hosts so building local pride and confidence (International Centre for Responsible Tourism (ICRT n.d.).

Such priorities also underpin Goodwin and Pender’s (2005) definition of responsible tourism, which although vague, echoes Cooper and Ozdil's (1992) point that shared responsibility is essential. In this instance they clarify the role of two key stakeholders - business and consumers. They assert responsible tourism is,

[a] business and consumer response to some of the major economic, social and environmental issues which affect our world. It is about travelling in a better way and about taking responsibility for the impacts that our actions have socially and economically on others and on their social, cultural and natural environment (Goodwin and Pender 2005:303).

Much of the discussion about responsibility in business and consumer lifestyles can be traced back to George Fisk who was one of the first to express concern over the global implications of mass production and consumption among the advanced nations of the world. His influential paper stressed individuals needed to take responsibility for limiting their personal consumption in order to encourage a rational and efficient (as opposed to extravagant and unnecessary) use of the world's resources (Fisk, 1973). Like Goodwin and Pender, and also Cooper and Ozdil, 
Fisk called for all stakeholders (business, government and consumers) to work together on joint initiatives to curb excessive consumption. He cited Margaret Mead's understanding of responsibility in support of his point,

...[R]esponsibility will include planning for lifestyles which are feasible economically and which will contribute to the sense of justice and dignity of all the people of the earth (Mead, 1970, as cited in Fisk, 1973:25).

Mead's explicit mention of the connections between responsible consumption, social justice and human dignity, emerged much later - in the definitions of responsible tourism presented earlier, and in the principles of the Cape Town Declaration (2002) on responsible tourism in destinations, the latter of which underpins the ICRT's definition of responsible tourism.

Expectations that people and also corporations should take responsibility for their individual and collective acts are much more widespread now than they were in 1973, largely due to the United Nation's emphasis on sustainable development goals to be embedded in targets for global growth, and public demand for transparency in business. Such developments have been fundamental to the increasing adoption of corporate social responsibility (CSR) as a benchmark of ethical business practice. However, while commercial entities, as well as non-governmental organisations (NGOs), have largely accepted the need to embrace the concept of responsibility in tourism, it appears that positive consumer response to this is somewhat inconsistent.

For example, apart from Tourism Concern, a UK campaign group for ethical and fairly traded tourism, there is little evidence of consumer-led calls for tourists to adopt higher ethical standards when travelling. Indeed, given the small number of responsible holidays sold, and studies revealing people want to relax and have fun rather than think about ethical issues on holiday, it appears tourists are unaware of or uninterested in the negative impact of their holidays on other people, cultures and environments. While research indicates neither consumers are aware of the issues (see Mintel 2012), there is clearly a gap between tourists' claimed intentions and their subsequent behaviour. The following section will tease out some 
of the background tensions to this situation and examine the extent to which such behaviour can be changed for the positive.

\section{Consumer demand for responsible tourism}

Given that tourism and travel industry actors are increasingly urged to take greater responsibility for their actions and to rely less on others to deliver positive behavioural change (Coles et al., 2013), it is unfortunate that consumers are not rising to the challenge and playing their part to achieve this. As noted in the previous section, a significant challenge facing those keen to increase demand for responsible tourism is that while there is evidence of interest among both suppliers and tourists, the numbers of holidays sold remains tiny. For example, in 2011, UK-based responsible tour operators sold holidays worth $£ 188$ million. While this is an increase of 154\% since 1999 (and an increase of 54\% since 2008) (Cooperative Bank, 2010, 2012), it is insignificant in comparison with the $£ 35$ billion UK outbound and domestic holiday market (Mintel 2012). With regard to consumers, more than 45 per cent of UK tourists do not want to think about ethical issues on holiday, and 49 per cent claim not to feel responsible for the environmental impact of their holidays (Mintel 2012).

Several reasons have been put forward as to why responsible tourism appears to be such a low priority for holidaymakers. These include consumers being confused about the array of labels (ethical, eco, sustainable, Fair Trade) used to describe responsible holidays. Also, while many tourists are adept at booking holidays independently, others may be challenged by the many inter-dependent components of the holiday business, and the sometimes-overwhelming amount of information needed to make what are often very complex bookings. Being required to read additional information about the ethical issues involved in their holidays increases the levels of decision-making for consumers, and may lead to information overload and subsequent disenfranchisement with the issue (Cherrier 2007). The desire to "switch off" from the concerns of everyday life is documented as another reason as to why tourists disregard ethical issues in tourism (Barr et al. 2010). Similarly, as noted in ethical consumer studies (Szmigin et al. 2009), 
tourists are likely to prioritise convenience, quality and price over ethical considerations in their decision-making. Such issues further challenge those operators who are keen to deliver responsible holidays, a point already been noted by the mass market as illustrated by the following quote,

[consumers will only] ... purchase more sustainably if it is easy to do so, affordable and well communicated. [TUI] are very aware that destination quality, attractiveness, weather and comfort levels are key determinants of customer decision-making, the quality of holiday experiences and thus our business success (Jane Ashton, TUI Travel’s Director of Group Sustainable Development, TUI Travel plc. 2010b:11).

Some people ignore the ethical issues completely yet buy responsible holidays because they want to experience a quality holiday, travel in a small group and interact meaningfully with local communities, all of which responsible operators generally provide (Weeden 2002). The ethical component for such individuals is an incidental bonus rather than a deliberate element in their decision-making. In this instance, promotional campaigns emphasising quality and authenticity will be more relevant to consumers than marketing material that tries to reinforce the ethical component of the holiday. This may explain why some or the SMME operators mute their ethical credentials (Weeden 2005).

Indeed, companies who bring ethical brands to the market with no penalty in terms of quality or price are considered most likely to succeed as such criteria are at the top of most consumers' priorities (Page and Fearn 2005). Potentially, such an approach might widen appeal for responsible travel beyond the niche of the committed ethical consumer, as well facilitate the incorporation of sustainable values in tourism development. Such a recommendation would certainly correspond with the perspective that responsible tourism is a guiding philosophy and not a niche product. Unfortunately, moving the operations industry towards the situation whereby they offer responsibility as standard, rather than as an add-on or a competitive 
opportunity, is unlikely to happen in the short term.

Aside from the competitive barriers to encouraging the supply of responsible holidays, perhaps the most significant challenge in the drive to encourage responsible tourism stems from people's holiday motivations being extremely complex and highly subjective. They also reflect a range of physical, psychological and aspirational factors. From the small number of responsible holidays being sold, it appears few people are willing to supplement a potentially extensive list of personal motivations with an equally large number of ethical considerations. Also, many people who claim to be concerned about ethical issues in tourism (see Tearfund 2000a, 2000b, 2001) change their minds, or do not act upon their intentions, at the point of purchase (Budeanu 2007; Choi and Sirakaya 2005; Hares et al. 2010; Miller et al. 2010; Sharpley 2000).

This gap between attitudes, intentions and behaviour has been extensively examined across all areas of the ethical consumer literature (Shaw and Clarke 1999; Shaw and Shiu 2003). It has also been addressed in tourism. For example, studies of consumer attitudes with regard to climate change and personal air travel reveal that holiday decision-making is perceived differently from that associated with everyday purchases. Using social practice theory, this research indicates holidays are considered "sacred" and explained as hard habits to break (Barr et al. 2010; Dickinson et al. 2010; Verbeek and Mommaas 2008). Even consumers who are environmentally focused in everyday life rationalise their less than ethical holiday choices with statements like, 'it is too difficult for me to change my behaviour', 'my actions as an individual won’t make any difference', and 'I protect the environment in other ways' (see Stoll-Kleemann et al. 2001:112). Such studies are not the focus of this chapter. Indeed, detail of consumer attitudes and their impact on behaviour can be found in greater detail elsewhere (Carrington et al. 2010). Rather, the focus of this chapter is to discuss how tour operators can use such information to market and promote responsible tourism. The following sections examine this in greater depth. 


\section{Tour operators and responsible tourism}

The previous section discussed some of the challenges facing operators who want to increase demand for responsible tourism. Indeed, through their supply of holiday and leisure experiences, tour operators are pivotal in the development of a responsible industry, and should be encouraged to do more to achieve this objective. Unfortunately, mass-market tour operators are often considered part of the problem and the "bad boys" of tourism. However, while they have been pilloried for destroying the social, cultural and environmental resources on which they rely (see McKercher 1993), there is evidence that many tour operators are passionate about delivering a responsible product (see Weeden 2005).

Arguably, a more accurate assessment of operators' potential contribution towards this goal would acknowledge the diverse nature of the different operations, both in size and offer, the financial imperatives of conducting business in such a highly competitive market, and the extensive efforts of many operators, not only to demonstrate their ethical credentials, but also to facilitate change in others. Admittedly, the majority of the latter tend to be small, medium and micro sized enterprises (SMMEs), whose owner-managers claim to feel a personal moral obligation to care about the impacts of their products and services (see Weeden 2005). The most prominent of such organisations operating out of the UK include Tribes Travel, Discovery Initiatives, Rainbow Tours, Steppes Discovery, Baobab Travel and Exodus Travel. Such companies are not confined to the UK - similarly motivated companies operate in all areas of the world.

Having noted the strong emphasis on responsibility from SMMEs operating in tourism, who rely on access to quality resources to compete effectively in an oligopolistic market place, there is also some evidence that the mass market is adapting its activities in line with calls for a more just and equitable system. Admittedly the evidence is patchy, but Europe’s largest operator, TUI Travel, arguably deserves credit for attempting to promote responsibility and sustainable practice. Widely recognised for their commitment to sustainable tourism, responsible 
leadership strategy and carbon reduction initiatives, TUI focuses on promoting a positive business case for responsibility in order to encourage other operators to follow suit. The company claims that acting responsibly enables them to attract investors, reduce costs, recruit quality staff, and improve the quality of their products (TUI Travel plc. 2010a). In combination, these benefits allow TUI to gain competitive advantage, which in turn enables them to spend money and time on protecting their access to social, cultural and environmental assets.

Cynics might argue such pronouncements are self-serving and merely marketing and public relations puffery, especially in light of TUI's First Choice brand controversially moving exclusively to all-inclusive hotels in summer 2012. However, it would be unfair to blame a single set of stakeholders for the relative status quo in the responsible tourism market, especially as commercial organisations, by definition, can only survive if they successfully fulfil customer needs. Indeed, tour operators who understand the wider importance of promoting responsible holidays face considerable challenge - not only must they secure profitable sales in an increasingly competitive global market, they also have to ensure supply chains conform to corporate promises on responsibility, and persuade consumers of the benefits of incorporating responsibility into their holiday decisions.

It is this latter issue that is one of the major obstacles to those seeking to develop responsible tourism beyond its somewhat niche status. Indeed, if European tourists are not interested in buying responsible holidays the industry must find new ways to encourage people to change, not only their attitudes, but also their behaviour. Such an objective has been discussed extensively in the climate change and tourism debate, with social practice theory being mooted as one explanation for the attitude-behaviour gap, as noted earlier (see Barr et al. 2010; Hares et al. 2010). Much of the literature generated by these studies also identify the potential of marketing to positively influence consumer behaviour change, but this remains relatively little discussed in terms of tour operators. Such an emphasis is the key focus of the following section, which discusses how operators commonly use marketing to promote responsible holidays, and considers some of the challenges associated with such activity. 


\section{Using the principles of marketing to sell ethical products}

With its roots in 1950s USA, marketing is a critical management function and an essential component in the effective promotion of products, services, ideologies and ideas (Belz and Peattie 2012). It has been defined as ‘. $\ldots$ organised effort, activity and expenditure designed first to acquire a customer and second to maintain and grow a customer at a profit' (Kotler et al. 2009:4). Similarly, the American Marketing Association clarify it as the 'activity, set of institutions, and processes for creating, communicating, delivering, and exchanging offerings that have value for customers, clients, partners and society at large' (in Pomering et al. 2011:958).

Unfortunately, given its pivotal role in influencing demand, society holds marketing and marketing professionals in very low esteem. Marketing activity is often perceived to be unethical, with marketers held responsible for consumers being persuaded to buy products and services they do not need, and for exploiting not only the people buying the products but also those producing them (Neyland and Simakova 2009). Those tasked with marketing products that have an ethical dimension (like responsible tourism) face even greater challenge because consumers' also exhibit extreme cynicism about the inherently unethical nature of the corporate world. Such mistrust and scepticism is in large part due to increasing (Internet) access to news media, citizen-consumer reports of dubious marketing practice, and the extensive levels of ethical and green wash in the 1980s (Peattie and Crane 2005).

How much people distrust an organisation that claims to be ethical seems to correspond with its size. For instance, mistrust is particularly prevalent when the vendor organisation is a large multinational corporation (de Pelsmacker et al. 2005). Arguably it is attitudes such as these that encourage many ethically-motivated organisations to play down their ethical, environmental and/or CSR achievements (Crane 1997). Indeed, companies with proactive CSR policies are often reticent to proclaim them for fear of being accused of exploiting moral obligation for the (cynical) pursuit of profit (Steger et al. 2007; van de Ven 2008). 
In light of such perceptions and in tandem with the rise of the citizen-consumer, marketing professionals are increasingly acknowledging the need to refocus their efforts to develop a sustainable approach to marketing. Initiated by Fisk’s concern about excessive consumption levels, and influenced, as noted earlier, by the emphasis on sustainable development in the United Nation’s Brundtland Report (World Commission on Environment and Development (WECD) 1987), sustainable marketing has been developed with the intention of combining the following: satisfying customer needs, meeting organisational goals, being compatible with ecosystems and cognisant of society’s long term needs (Fuller 1999). Sustainable marketing in tourism places emphasis on sustainability at each stage in the process of marketing, on the premise that marketing is 'a way of doing business rather than a mere managerial function' (Pomering et al. 2011:955) These authors argue that traditional marketing mixes do not address broader societal concerns, and believe,

The concept of the marketing mix is the ideal checklist for examining what tourism organisations currently do and how they might more appropriately meet increasing sustainability demands. The elements of the marketing mix are captured in the core values of the organisation, reflecting the nature of its relationships with key stakeholders, such as suppliers, consumers, employees, host communities and the environment. These relationships signal the degree of the organisations' sustainability orientation (Pomering et al. 2011:961).

In common with responsible tourism, sustainable marketing has spawned a number of labels including green, ecological, social and societal marketing, which to some extent has resulted in confusion and also misunderstanding (Belz and Peattie 2012; Fuller 1999). Also, like responsible tourism, it has been the focus of debate, with some arguing the term is an oxymoron (Fuller, 1999), and asserting 'marketing [is] traditionally considered an enemy of sustainability’ (Pomering et al. 2011:953). This latter point is critical to those promoting responsible holidays. Indeed, tourism marketing has been criticised for focusing too much on opportunities for economic growth and too little on the impact of tourism development on people, places and the 
environment (Jamrozy 2007). It is also blamed for encouraging tourists to believe greater levels of "happiness" can be attained with each additional holiday purchase, a theme evident in many areas of modern life (Kasser 2004).

\section{Social marketing in tourism}

It is clear from the discussions in this chapter so far that marketing is often perceived negatively. As such, it is not surprising that those who use it for professional reasons have sought to ally themselves with a more sustainable remit. However, it is by far the only initiative tasked with the rehabilitation of marketing as a socially positive function. For example, although it shares similar objectives with sustainable marketing, social marketing has lately been lauded as the most effective way of influencing, changing and/or preventing behaviour (see Belz and Peattie 2012). It is most commonly observed in campaigns associated with health, where it is used to discourage harmful behaviour, such as drug and alcohol addiction, or to promote positive physical activity aimed at improving individual health and wellbeing.

In its purest form, the primary difference for social marketing is that it aims to benefit targeted individuals, groups and society, whereas the objective of traditional marketing is to benefit the organisation carrying out the promotional activity (Andreasen 1994). Social marketing, a term first coined by Kotler and Zaltman in 1971, has been defined as, 'the adaptation of commercial marketing technologies to programmes designed to influence the voluntary behaviour of target audiences to improve their personal welfare and that of the society of which they are a part' (Andreasen 1994:110). Whilst using similar techniques, social marketing differs from traditional marketing because of an emphasis on,

... understanding and overcoming barriers to behavioural change. Where a commercial marketing approach might begin by asking why people might buy this coffee, and how they can be encouraged to do so, a social marketing approach would first seek to understand why most do not buy it, and how their objections might be overcome ... for a product seeking to move beyond a market niche, tackling the reason 
for non-purchase amongst the majority of consumers is crucial (Golding and Peattie 2005:160).

The utility of social marketing to influence consumer demand for responsible tourism has been noted for some time. For example it is more than a decade since Dinan and Sargeant (2000) first suggested ecotourism destinations could adopt its techniques to target tourists already predisposed to act sustainably. Significantly, however, it is also critical if seeking to activate “new” patterns of behaviour, making it useful for widening demand for responsible tourism by reaching out to tourists not yet convinced of the need to adopt such behaviour. Indeed, given the prevalence of the attitude-behaviour gap, whereby consumers express concern but take no action, a technique that encourages people to change their behaviour is definitely worth exploring, not only to increase consumer demand for responsible holidays but to persuade the industry to adopt more responsible forms of development.

This is the key challenge for any initiative aimed at modifying human behaviour; people are notoriously reluctant to abandon their habitual life patterns (Dinan and Sargeant 2000), particularly if addiction is involved. This is highly relevant in tourism and travel, where travellers have been labelled as displaying an addiction to flying (Cohen et al. 2011). Although this might initially be interpreted as an extreme view, behaviour commonly associated with addiction, such as patterns of denial, suppression of guilt, an off-loading of responsibility and failed attempts to end destructive behaviour, certainly has resonance in tourist research and an improved understanding of addictive behaviours may contribute to greater knowledge of the factors involved in the attitude-behaviour gap. Certainly the conceptualisation of tourist inertia (express concern but do nothing) as an "addiction” merits further research attention (for more debate on this issue see Gössling 2013) .

Of course, no single solution will ever be sufficient to overcome the complex set of challenges faced by those wanting to promote responsible tourism to society, and social marketing is no exception to this. Indeed, while it may assist in communicating the benefits of tourism, and 
promoting social equity and international understanding through its operation (Jamrozy 2007), there are several reasons why it might be difficult to encourage the travel industry to fully endorse the techniques associated with it. Firstly, social marketing is considered by many to be the remit of public and non-profit organisations rather than the private sector. Secondly, a key objective of social marketing is to enhance society's wellbeing. This would be challenging for any tour operator, especially a public company, as investors may be less interested in social benefits and more concerned with share dividends. Thirdly, when the objects of the campaign are in a far-off country, as they are likely to be for many holidays, the object of the campaign is so far removed from the consumer that it will be a challenge to make the connection meaningful (Weeden 2013).

\section{Conclusion}

Given the extensive list of challenges so far discussed in this chapter regarding the marketing of ethical products and the related problems of incorporating ethical messages in holiday promotion, how might the industry move forward to embrace a sustainable future, at the same time as encourage a greater demand for responsible travel? There are of course many group initiatives already in existence, which have been formed specifically with these joint objectives in mind. For example, Tourism Concern’s Ethical Tour Operator Group (ETOG) focuses on providing support and encouragement to tourism SMEs to provide ethical and fairly traded tourism. A different programme, the Tour Operators’ Initiative (TOI), involves a range of tour operators, including TUI plc and Accor, who work together with UNEP and UNWTO to support sustainable tourism development.

With regard to the tourist, Stanford (2008:270) suggests appealing to those who already exhibit elements of responsible consumption economically, environmentally or culturally, 'to demonstrate a greater degree of responsibility within the dimensions they already practice'. This group of consumers could be potentially significant in terms of increasing demand for responsible tourism. For example, while nearly half of UK consumers do not feel responsible 
for the impact of their holidays, 32 per cent are unsure with a similar number claiming not to know whether they want to think about ethics on holiday (Mintel 2012). The existence of such a group, and their potential for persuasion, has also been recognised by TUI,

[a] lthough there is not an active majority that consider sustainability as an integral part of their decision-making process, industry should look promisingly at the large number of ambivalent consumers that are within the field of influence. Consumer demographics demonstrate divergence in attitudes towards sustainability amongst different consumer groups but encouragingly, no particular group in terms of age or lifestyle (Jane Ashton, Director for Sustainable Development, TUI Travel Plc. 2010:11).

Such ideas have their roots firmly in the marketing domain where efforts to increase usage (and therefore purchase of a product or service) from light to heavy are seen as essential in campaigns to cost-effectively increase demand. However, and this is the nub of the issue - how might the tour operations industry collectively move tourists towards an expectation of responsibility from operators, whilst encouraging them to accept they also have a personal role to play? The industry is notoriously competitive and run on very tight financial margins. Such extreme trading conditions, almost inevitably lead to power struggles between all operators, large and small. While much of the literature on responsible tourism has called for collaboration and cooperation amongst all stakeholders, the industry at present shows little sign of moving towards this - apart from voluntary initiatives, the competition is as tight as ever.

Consumers believe they benefit from such competition, not least because of the impact it has on the price they pay for their holidays. Competition does not however automatically increase quality, and quality holidays will be the domain of future developments in sustainability and responsible tourism. Unless everyone, supplier and consumer alike, work together to achieve such an objective, a truly responsible industry will be difficult to secure. Tourists remain at the heart of the tourism industry and so efforts to encourage them to embrace responsible tourism 
are essential. While all tour operators ought to be more proactive in the development of a responsible industry, every industry actor needs to do more to deliver leisure and business experiences that provide beneficial relationships and positive financial outcomes for all, not only to secure the future of the industry but also to protect the social, cultural and natural assets on which they depend.

\section{References}

Andreasen, Alan R. (1994) 'Social Marketing: Definition and Domain’, Journal of Marketing and Public Policy Spring: 108-114.

Barr, S., Shaw, G., Coles, T. and Prillwitz, J. (2010) ‘A Holiday is a Holiday’: Practicing Sustainability, Home and Away', Journal of Transport Geography 18 (3): 474-481.

Belz, F-M. and Peattie, K. (2012) Sustainability Marketing: A Global Perspective, (2 ${ }^{\text {nd }}$ edn) Chichester: John Wiley \& Sons Ltd.

Bramwell, B., Lane, B., McCabe, S. Mosedale, J. and Scarles, C. (2008) ‘Research Perspectives on Sustainable Tourism', Journal of Sustainable Tourism 16 (3): 253-257.

Budeanu, A. (2007) 'Sustainable Tourist Behaviour: A Discussion of Opportunities for Change', International Journal of Consumer Studies 31 (5): 499-508.

Cape Town Declaration (2002) 'Responsible Tourism in Destinations', www.responsibletourismpartnership.org/CapeTown.html, accessed 12 June 2013.

Carrington, M.J., Neville, B.A. and Whitwell, G.J. (2010) ‘Why Ethical Consumers Don’t Walk their Talk: Towards a Framework for Understanding the Gap Between the Ethical Purchase Intentions and Actual Buying Behaviour of Ethically Minded cCnsumers', Journal of Business Ethics 97 (1): 139-158.

Cherrier, H. (2007) 'Ethical Consumption Practices: Co-production of Self-Expression and Social Recognition', Journal of Consumer Behaviour 6 (5): 321-225.

Choi, H. S and Sirakaya, E. (2005) 'Measuring Resident Attitudes Toward Sustainable Tourism: Development of a Sustainable Tourism Attitude Scale', Journal of Travel Research 43(4): 380-394. 
Cleverdon, R. and Kalisch, A. (2000) ‘Fair Trade in Tourism', International Journal of Tourism Research 2 (3): 171-187.

Cohen, S.A., Higham, J.E.S. and Cavaliere, C. T. (2011) ‘Binge Flying: Behavioural Addiction and Climate Change’, Annals of Tourism Research 38 (3): 1070-1089.

Coles, T., Fenclova, E., and Dinan, C. (2013) ‘Tourism and Corporate Social Responsibility: A Critical Review and Research Agenda’, Tourism Management Perspectives 6: 122-141.

Cooper, C.P., and Ozdil, I. (1992) 'From Mass to "Responsible” Tourism: The Turkish Experience', Tourism Management 13 (4): 377-386.

Cooperative Bank (2010) Ten Years of Ethical Consumerism: 1999-2008, www.goodwithmoney.co.uk (accessed 11 June 2010).

Cooperative Bank (2012) Ethical Consumers Market Report 2012, www.cooperative.coop/corporate/Investors/Publications/Ethical-Consumerism-Report/, (accessed 4 January 2013).

Crane, A. (1997) 'The Dynamics of Marketing Ethical Products: A Cultural Perspective', Journal of Marketing Management 16 (6): 561-577.

De Pelsmacker, P., Janssens, W., Sterckx, E., and Mielants, C. (2005) 'Consumer Preferences for the Marketing of Ethically Labelled Coffee’, International Marketing Review 22 (5): 512530.

Dickinson, J. E., Robbins, D. and Lumsdon, L. (2010) 'Holiday Travel Discourses and Climate Change', Journal of Transport Geography 18 (3): 482-489.

Dinan, C. and Sargeant, A. (2000) 'Social Marketing and Sustainable Tourism: Is There a Match?', International Journal of Tourism Research 2 (1):1-14.

Eagles, P.F.J., McCool, S.F. and Haynes, C.D.A. (2002) 'Sustainable Tourism in Protected Areas: Guidelines for Planning and Management', Switzerland and Cambridge: IUCN Gland, www.cmsdata.iucn.org/downloads/pag_008.pdf (accessed 16 June 2013).

Fisk, G. (1973) ‘Criteria for a Theory of Responsible Consumption’, Journal of Marketing 37 (2): 24-31. 
Font, X. and Ahjem, T.E. (1999) Searching for a Balance in Tourism Development Strategies, MCB Virtual Conference Centre, MCB University Press.

Forsyth, T. (1997) 'Environmental Responsibility and Business Regulation: The Case of Sustainable Tourism', The Geographical Journal 16 (3): 270-280.

Frey, N. and George, R. (2008) 'Responsible Tourism and the Tourism Industry: A Demand and Supply Perspective', in A. Spenceley (ed.) Responsible Tourism: Critical Issues for Conservation and Development, Gateshead: Earthscan, 107-128.

Fuller, D.A. (1999) Sustainable Marketing: Managerial-Ecological Issues, Thousand Oaks, CA: Sage Publications, Inc.

Golding, K. and Peattie, K. (2005) 'In Search of a Golden Blend: Perspectives on the Marketing of Fair Trade Coffee’, Sustainable Development 13 (3): 154-165.

Goodwin, H. and Pender, L. (2005) 'Ethics in Tourism Management', in L. Pender, and R. Sharpley (eds) The Management of Tourism, London: Sage Publications, 288-304.

Gössling, S. (2013) ‘Advancing a Clinical Transport Psychology’, Transportation Research Part F: Traffic Psychology and Behaviour 19:11-21.

Hares, A., Dickinson, J., \& Wilkes, K. (2010) ‘Climate Change and the Air Travel Decisions of UK Tourists', Journal of Transport Geography 18 (3): 466-473.

Higgins-Desbiolles, F. (2008) 'Justice Tourism and Alternative Globalisation', Journal of Sustainable Tourism 16 (3): 345-364.

Hultsman, J. (1995) 'Just Tourism, an Ethical Framework’, Tourism Management 11 (9): 553567.

ICRT (n.d) Responsible tourism, www.icrtourism.org/responsible-tourism/, (accessed 27 June 2013).

Jamrozy, U. (2007) 'Marketing of Tourism: A Paradigm Shift Toward Sustainability', International Journal of Culture, Tourism and Hospitality Research 1 (2): 117 - 130.

Kalisch, A. (2001) Tourism as Fair Trade, NGO Perspectives, London: Tourism Concern. 
Kasser, T. (2004) 'The Good Life or the Goods Life? Positive Psychology and Personal Wellbeing in the Culture of Consumption', in P.A. Linley and S. Joseph (eds) Positive Psychology in Practice, Hoboken, New Jersey: John Wiley and Sons, Inc, 55-67.

Kotler, P., Keller, K.L., Brady, M., Goodman, M. and Hansen, T. (2009) Marketing Management, Harlow: Pearson Education Ltd.

Leslie, D. (ed.) (2012) Responsible Tourism: Concepts, Theory and Practice, Wallingford, Oxfordshire: CAB International.

McKercher, B. (1993) ‘Some Fundamental Truths About Tourism: Understanding Tourism’s Social and Environmental Impacts', Journal of Sustainable Tourism, 1(1):6-16.

Miller, S. and Gregan-Paxton, J. (2006) 'Community and Connectivity: Examining the Motives Underlying the Adoption of a Lifestyle of Voluntary Simplicity', Advances in Consumer Research 33: 289.

Mintel (2012) Holiday Review - UK - January 2013.

Neyland, D. and Simakova, E. (2009) 'How Far Can we Push Sceptical Reflexivity? An Analysis of Marketing Ethics and the Certification of Poverty', Journal of Marketing Management 25 (7/8): 777-794.

Nunkoo, R. and Ramkissoon, H. (2010) 'Gendered Theory of Planned Behaviour and Residents’ Support for Tourism', Current Issues in Tourism 13(6): 525-540.

Page, G. and Fearn, H. (2005) 'Corporate Reputation: What do Consumers Really Care About?', Journal of Advertising Research 45 (3): 305-313.

Payne, D. and Dimanche, F. (1996) 'Towards a Code of Conduct for the Tourism Industry: An Ethics Model', Journal of Business Ethics 15 (9): 997-1007.

Peattie, K. and Crane, A. (2005) 'Green Marketing: Legend, Myth, Farce or Prophesy?', Qualitative Market Research: An International Journal, 8 (4): 357-370.

Pomering, A., Nobel, G. and Johnson, L.W. (2011) 'Conceptualising a Contemporary Marketing Mix for Sustainable Tourism', Journal of Sustainable Tourism 19(8): 953-969.

Scheyvens, R. (2002) Tourism for Development: Empowering Communities, Harlow: Prentice Hall. 
Sharpley, R.A.J. (2000) 'Tourism and Sustainable Development: Exploring the Theoretical Divide', Journal of Sustainable Tourism 8 (1): 1-19.

Shaw, D. and Clarke, I. (1999) 'Belief Formation in Ethical Consumer Groups: An Exploratory Study’, Marketing Intelligence and Planning 17 (2): 109-119.

Shaw, D. and Shiu, E. (2003) 'Ethics in Consumer Choice: A Multivariate Modelling Approach', European Journal of Marketing 37 (10):1485-1498.

Stanford, D. (2008) '”Exceptional” Visitors: Dimensions of Tourist Responsibility in the Context of New Zealand', Journal of Sustainable Tourism 16 (3): 258-275.

Steger, U., Ionescu-Somers, A. and Salzmann, O. (2007) 'The Economic Foundations of Corporate Sustainability’, Corporate Governance 7(2): 162-77.

Stoll-Kleemann, S., O’Riordan, T. and Jaeger, C.C. (2001) 'The Psychology of Denial Concerning Climate Mitigation Measures: Evidence from Swiss Focus Groups', Global Environmental Change 11:107-117.

Szmigin, I., Carrigan, M. and McEachern, M.G. (2009) 'The Conscious Consumer: Taking a Flexible Approach to Ethical Behaviour', International Journal of Consumer Studies 33 (2): 224-231.

Tearfund (2000a) 'A Tearfund Guide to Tourism: Don't Forget your Ethics!', www.tearfund.org, (accessed 11 January 2000).

--(2000b) 'Tourism: An Ethical Issue', January, www.tearfund.org, (accessed 11 January 2000).

--(2001) 'Tourism: Putting Ethics into Practice', January, www.tearfund.org, (accessed 20 February 2001).

TUI Travel plc. (2010a) The Business Case for Sustainable Tourism, www.tuitravelplc.com/sustainability/in-focus/business-case-sustainable-tourism (accessed 13 June 2013).

TUI Travel plc. (2010b) Tourism Future, www.tuitravelplc.com (accessed 13 June 2013). 
UNWTO (2011) 'Tourism Towards 2030: Global Overview', www.pub.unwto.org/.../111014_TT_2030_global_overview_excerpt.pdf, （accessed 20 November 2012).

--(2012a) 'International Tourism to Reach one Billion in 2012', www.media.unwto.org/en/press-release/2012-01-16/international-tourism-reach-one-billion2012, (accessed 3 October 2012).

--(2012b) 'Presentation: World Tourism Performance 2011 and Outlook 2012', www.media.unwto.org/en/press-release/2012-01-16/international-tourism-reach-one-billion2012, (accessed 20 November 2012).

Van de Ven, B (2008) 'An Ethical Framework for the Marketing of Corporate Social Responsibility', Journal of Business Ethics 82 (2):339-352.

Verbeek, D. and Mommaas, H. (2008) 'Transitions to Sustainable Tourism Mobility: The Social Practices Approach', Journal of Sustainable Tourism, 16(6): 629-644.

Wearing, S. (2002) ‘Re-centring the Self in Volunteer Tourism’, in G.S. Dann (ed.) The Tourist as a Metaphor of the Social World, Wallingford, Oxfordshire: CAB International, 237-262.

WECD (1987) The Brundtland Report (Our Common Future), Oxford: Oxford University Press.

Weeden, C. (2002) 'Ethical Tourism: An Opportunity for Competitive Advantage?’, Journal of Vacation Marketing 8 (2): 141 - 153.

--(2005) 'Ethical Tourism: Is it future in Niche Tourism?’, in M. Novelli (ed.) Niche Tourism, Oxford: Butterworth-Heinemann, 233-245.

--(2013) Responsible Tourist Behaviour, London: Routledge. 
